\title{
"Isso eu acho no grupo": Grupos de terceira idade e o emergir de faces ocultas da sexualidade
}

\author{
"That's what I believe while in the group": Third age groups and the emerging of hidden faces of \\ sexuality
}

"Que pienso en el grupo": Grupos de tercera edad y la emergencia de caras ocultas de sexualidade

Recebido: 05/05/2021 | Revisado: 12/05/2021 | Aceito: 13/05/2021 | Publicado: 31/05/2021

\author{
Larissa Venturini \\ ORCID: https://orcid.org/0000-0002-5401-3849 \\ Universidade Federal de Santa Maria, Brasil \\ E-mail: larissa.venturini@ufsm.br \\ Margrid Beuter \\ ORCID: https://orcid.org/0000-0002-3179-9842 \\ Universidade Federal de Santa Maria, Brasil \\ E-mail: margridbeuter@gmail.com \\ Jamile Lais Bruinsma \\ ORCID: https://orcid.org/0000-0001-8861-1321 \\ Universidade Federal de Santa Maria, Brasil \\ E-mail: jamilebruinsma@hotmail.com \\ Carolina Backes \\ ORCID: https://orcid.org/0000-0002-2504-9105 \\ Universidade Federal de Santa Maria, Brasil \\ E-mail: karolbackes@hotmail.com \\ Eliane Raquel Rieth Benetti \\ ORCID: https://orcid.org/0000-0003-1626-5698 \\ Universidade Federal de Santa Maria, Brasil \\ E-mail: elianeraquelr@yahoo.com.br \\ Paloma Horbach da Rosa \\ ORCID: https://orcid.org/0000-0003-4463-1042 \\ Universidade Federal de Santa Maria, Brasil \\ E-mail: palomahorbach93@hotmail.com \\ Francine Feltrin de Oliveira \\ ORCID: https://orcid.org/0000-0002-5105-7053 \\ Universidade Federal de Santa Maria, Brasil \\ E-mail: francinefeltrin@uol.com.br \\ Sandra da Silva Kinalski \\ ORCID: https://orcid.org/0000-0002-4841-2288 \\ Universidade Federal de Santa Maria, Brasil \\ E-mail: sandrakinalski@yahoo.com.br \\ Caren da Silva Jacobi \\ ORCID: https://orcid.org/0000-0002-8917-6699 \\ Universidade Federal de Santa Maria, Brasil \\ E-mail: cahjacobi@gmail.com
}

\begin{abstract}
Resumo
Objetivo: descrever a influência de grupos de terceira idade na sexualidade de idosos. Metodologia: Trata-se de um estudo descritivo, exploratório, de abordagem qualitativa, realizado com 15 idosos participantes de um grupo de terceira idade. Os dados foram coletados em outubro de 2014, por meio do método criativo-sensível, com a realização da dinâmica almanaque e submetidos à análise de discurso pecheutiana. Resultados: O grupo de terceira idade mostrase como um espaço que exerce relevante influência à sexualidade de idosos, manifestando-se como lócus que favorece a criação e manutenção de laços de amor, que possibilita o despertar e a compreensão da sexualidade de forma multidimensional e que fornece suporte a superação de preconceitos e tabus. Conclusão: Cabe aos profissionais de saúde vislumbrar faces, talvez ocultas, e direcionar suas atuações, ocupando-se destes espaços por meio de atividades de promoção e prevenção em saúde, com vistas ao planejamento de ações específicas e objetivando a atenção integral ao idoso.
\end{abstract}

Palavras-chave: Idoso; Sexualidade; Saúde do Idoso. 


\begin{abstract}
Objective: to describe the influence of elderly groups on the sexuality of the elderly. Methodology: This is a descriptive, exploratory study, with a qualitative approach, carried out with 15 elderly people participating in a group of senior citizens. The data were collected in October 2014, using the creative-sensitive method, with the realization of the almanac dynamics and submitted to the analysis of the Pecheutian discourse. Results: The elderly group shows itself as a space that exerts a relevant influence on the sexuality of the elderly, manifesting itself as a locus that favors the creation and maintenance of bonds of love, which enables the awakening and understanding of sexuality in a multidimensional way and that provides support to overcome prejudices and taboos. Conclusion: It is up to health professionals to glimpse faces, perhaps hidden, and direct their actions, taking care of these spaces through health promotion and prevention activities, with a view to planning specific actions and aiming at comprehensive care for the elderly.
\end{abstract}

Keywords: Aged; Sexuality; Health of the elderly.

\title{
Resumen
}

Objetivo: describir la influencia de los grupos de ancianos en la sexualidad de los ancianos. Metodología: Se trata de un estudio descriptivo, exploratorio, con enfoque cualitativo, realizado con 15 personas mayores que participan en un grupo de personas mayores. Los datos fueron recolectados en octubre de 2014, utilizando el método creativo-sensible, con la realización de la dinámica del almanaque y sometidos al análisis del discurso pecheutiano. Resultados: El grupo de ancianos se muestra como un espacio que ejerce una influencia relevante sobre la sexualidad de los ancianos, manifestándose como un locus que favorece la creación y mantenimiento de lazos de amor, lo que posibilita el despertar y la comprensión de la sexualidad de manera multidimensional. y que brinda apoyo para superar prejuicios y tabúes. Conclusión: Corresponde a los profesionales de la salud ver rostros, quizás ocultos, y orientar sus acciones, cuidando estos espacios a través de acciones de promoción y prevención de la salud, con miras a planificar acciones concretas y orientadas a la atención integral a las personas mayores.

Palabras clave: Anciano; Sexualidad; Salud del anciano.

\section{Introdução}

As transformações que circundam as esferas sociais, econômicas, políticas e tecnológicas vêm repercutindo significativamente no aumento da longevidade da população brasileira. O crescimento da expectativa de vida, considerado uma grande conquista da humanidade, fomenta considerações ao fato de que viver mais não significa necessariamente viver bem.

Os dados demográficos e epidemiológicos incitam a necessidade de promover a melhoria da qualidade de vida e oportunidades para as pessoas idosas (IBGE, 2018). Assim, tem-se buscado, cada vez mais, compreender o processo de envelhecimento populacional e cooptar alternativas a fim de manter os idosos socialmente integrados. Uma das formas de promover a inserção da pessoa idosa na sociedade é por meio da participação em grupos de terceira idade, os quais influenciam positivamente na saúde física e mental (Miranda, Mendes \& Silva, 2016; Reis \& Cassino, 2017).

Os grupos de terceira idade, também denominados grupos de convivência, constituem-se como espaços que valorizam a potencialidade dos idosos, e mostram-se como uma forma de interação, propiciando a efetivação de laços de amizade, momentos de lazer e de viver com dignidade. Assim, contribuem para a saúde dos indivíduos idosos, ao reestabelecer a autoimagem positiva, autonomia e independência (Schoffen \& Santos, 2018).

Nesse contexto, apresentam-se como uma forma de minimizar a solidão, estimular o contato social e a descoberta de novas aptidões (Schoffen \& Santos, 2018). Esses grupos propiciam um compromisso regular, que não apenas ocupa um espaço temporal, mas também os integra a uma rede social repercutindo na dignidade e qualidade de vida dos idosos (Previato et al, 2019). Além disso, a participação nos grupos contribui para construção de laços de amizades e até mesmo de amor (Valer, Bierhals, Aires \& Paskulin, 2015).

Tangenciar sexualidade e envelhecimento origina inúmeras subjeções e estigmas (Uchôa et al, 2016). Assim, apesar das repressões culturais, sociais e de gênero, nos grupos de terceira idade revelam-se, por vezes, possibilidades para novas experiências e vivências afetivas (Valer et al, 2015).

Neste artigo, a sexualidade é entendida numa perspectiva ampla, vista como uma manifestação presente em todas as fases da vida de um ser humano. Assim, compreende todas as dimensões do ser humano estando presente no conjunto de 
experiências e sensações de bem-estar; resultantes do conforto físico e emocional. Manifesta-se em todos os momentos da vida e estão intimamente relacionadas com a história, os costumes, os desejos, as emoções e a educação de cada indivíduo (Oliveira, Neves \& Silva, 2018).

A sexualidade é compreendida como parte integrante do ser humano e reconhecida como um fator determinante da saúde dos idosos. Observa-se, no senso comum, a etapa da terceira idade como um período de 'assexualidade' e de renúncias, esquecendo-se de suas vontades, desejos e direitos. Nesse sentido, é preciso desmitificar a concepção arraigada da sociedade de que a sexualidade é prerrogativa da juventude (Saraiva, Rosas, Marques, Valente, 2018).

No exercício dos profissionais de saúde considerar a sexualidade como integrante em intervenções junto à população idosa, requer seriedade e dignidade. Repensar as práticas adotadas e considerar a escassez da abordagem desta temática pelos profissionais denota a necessidade de estudos, reflexões e tratativas, a fim de afastar os preconceitos que produzem estigmas e marginalizam a sexualidade na terceira idade (Oliveira, Neves \& Silva, 2018).

Em decorrência da repercussão que a sexualidade gera na saúde física e mental dos indivíduos, assim como, o observável aumento da expectativa de vida da população, o que tem levado os idosos a procurarem novas formas de vivenciar o envelhecimento, os grupos de terceira idade revelam-se como espaços cada vez mais procurados e valorizados por essa população. Nesse sentido, o presente estudo objetiva descrever a influência de grupos de terceira idade na sexualidade de idosos.

\section{Metodologia}

Trata-se de um estudo de campo, de caráter descritivo e exploratório, com abordagem qualitativa. A população do estudo contemplou idosos participantes de um grupo de terceira idade, localizado na região central do Estado do Rio Grande do Sul (RS), Brasil.

O Grupo de terceira idade em questão possui em torno de 116 idosos que participam de atividades físicas, de integração, artísticas, turismo e ações sociais. Essas ocorrem de segunda a sexta-feira, com cronograma divulgado no início de cada mês.

Os dados foram coletados, em outubro de 2014, seguindo pressupostos do Método Criativo Sensível (MCS). O eixo do método é a Dinâmica de Criatividade e Sensibilidade (DCS) que conjuga produções artísticas com a discussão grupal e a observação participante. Nas práticas grupais de pesquisa o participante produz, atribui sentido ao que produziu e ressignifica suas enunciações, coletivizando experiências internalizadas no convívio e na práxis social (Cabral \& Moraes, 2015).

Optou-se pela DCS "Almanaque", obtendo por meio de colagem de figuras e desenhos em folhas A4 respostas à questão geradora de debate: "Como o grupo de terceira idade influencia na vivência da sua sexualidade?" Participaram da pesquisa um total de 15 idosos, que estavam frequentando o grupo há pelo menos seis meses, convidados aleatoriamente. Foram realizadas duas dinâmicas, com um grupo de dez e cinco idosos, respectivamente. As dinâmicas foram gravadas em áudio e a produção artística foi fotografada. A realização das dinâmicas ocorreu em horário de disponibilidade dos participantes, nas dependências do grupo, com duração média de 90 minutos.

A dinâmica "Almanaque" ocorreu em cinco momentos que seguem: $1^{\circ}$ momento: recepção dos idosos e apresentação das próximas etapas; $2^{\circ}$ momento: disponibilização de figuras (aproximadamente 200), as quais versavam sobre aspectos da natureza, objetos, pessoas e relações, neste momento também foi apresentada a questão geradora de debate; $3^{\circ}$ momento: construção individual do almanaque; $4^{\circ}$ momento: apresentação individual da produção artística de cada participante e discussão coletiva, quando começaram a surgir situações existenciais dos participantes, a partir das quais eles concordaram e/ou discordaram dos outros participantes; $5^{\circ}$ momento: síntese e a validação dos dados.

A análise dos dados fundamentou-se na Análise de Discurso (AD) francesa Pecheutiana. A AD consiste na análise de 
unidades texto para além da análise da frase, assim, procura identificar o que está além da superficialidade do discurso, inserindo-o no contexto vivenciado pelos enunciantes e valorizando aspectos históricos e sociais (Pêcheux, 2009).

Para a organização e análise dos dados foram elaborados quadros analíticos contendo a situação existencial dos idosos participantes de grupos de terceira idade, que emergiram no interior da dinâmica, o tema gerador, a recodificação temática e o comentário analítico do processo interpretativo. Os temas foram desvelados de acordo com as manifestações dos participantes, originando uma discussão sobre a influência de grupos de terceira idade na sexualidade de idosos.

Esta pesquisa foi aprovada pelo Comitê de Ética em Pesquisa sob parecer $\mathrm{n}^{\circ} 718.921$, de julho de 2014, sendo respeitadas as normas da legislação brasileira para pesquisas com seres humanos. A fim de preservar a identidade dos participantes do estudo, foram identificados com a letra $\mathrm{P}$, seguidos de uma numeração sequencial, de acordo com a transcrição dos dados.

\section{Resultados e Discussão}

Participaram do estudo dez mulheres e cinco homens, com idade entre 60 e 80 anos (sete participantes encontravamse na faixa etária dos 66 aos 70 anos). Dos 15 idosos participantes, sete eram casados, cinco eram viúvos, dois solteiros e um separado. Com relação ao tempo de participação no grupo de terceira idade, para oito participantes variou entre um e três anos, para quatro participantes entre três e sete anos e superior há sete anos para outros três participantes.

Os temas surgiram no desenvolvimento das DCS Almanaque I e II, em que o imaginário dos sujeitos foi materializado em produções artísticas e relatos retratando suas vivências, experiências e buscando responder à questão norteadora: "como os grupos de terceira idade influenciam na sexualidade de idosos?"

\subsection{Grupos de terceira idade favorecendo a criação e manutenção de laços de amor}

A convivência em grupos de terceira idade abarca oportunidades e desfechos, que são explorados e construídos pelas ideologias e pelo desejo inconsciente materializado na e pela linguagem. As construções imaginárias perpassam os lugares que os sujeitos ocupam na sociedade e nos discursos, evidenciando esses grupos como espaços sociais que descortinam e (re)significam o prisma do envelhecimento.

Eu conheci uma pessoa no grupo, um companheiro. Eu precisava mesmo de uma pessoa mais próxima. No grupo a gente tem a oportunidade de conhecer pessoas da nossa idade, ele cria laços além de amizade, pode criar também de amor $(P 2)$.

Aqui é diferente, é o único lugar que facilita, quantos que se conheceram no grupo e já casaram, se ajuntaram, começa de brincadeira (P10).

Tem muitas e muitos que ocupam do grupo para fisgar novos relacionamentos, acho que é porque o grupo deixa a gente mais próximos (P11).

A enunciação dialógica dos participantes desvela que o grupo permite aproximação e oportunidades, permitindo tomadas de posição sujeito acerca da sexualidade. A criação destes vínculos decorre em virtude de o grupo oportunizar a convivência de pessoas com faixas etárias semelhantes e que possuem objetivos e expectativas similares.

Os grupos de terceira idade oferecem oportunidades sociais, colaborando para que o idoso se torne ativo, participativo e vislumbra possibilidades para construção de sua identidade. Assim, mostram-se como espaços de socialização dos idosos onde possam compartilhar vivências, práticas, construir novas amizades, paquerar, namorar, dançar, sentirem-se valorizados e socializados (Carvalho et al, 2016; Marques et al, 2015). 
Os idosos veem os grupos de terceira idade como um lugar de referência, buscam e encontram nestes espaços companheirismo, relações de amizade e, por vezes, se deparam com o amor. O desenvolver das diversas atividades do grupo é o que permite entrosamento e aproximação entre os membros.

As atividades desenvolvidas dentro do espaço dos grupos contemplam diversas dimensões da vida humana como os aspectos lúdicos, de lazer, sociais e de saúde, deste modo, favorecendo a construção do conhecimento, a expressão e a aproximação entre os participantes. As condições de produção perpassam contornos decisivos para a construção da identidade dos idosos e, assim, no reconhecimento de espaços que interferem, contemplam ou permitem ocultar ou descortinar aspectos privados de suas vidas.

Meu namorado é de outro grupo. Conheci ele em um baile que teve com vários grupos. Minha rotina era só ficar em casa, o grupo que abre possibilidades (P12).

Essa daqui (se referindo a uma das imagens que compõem seu almanaque) representa pessoas se conhecendo, o que vale para meu caso, através das atividades de câmbio (jogo de vôlei adaptado para terceira idade), os bailes e os jogos de canastra é que eu tive a oportunidade de me aproximar de uma pessoa e respondendo tua pergunta, despertar a minha sexualidade (P2).

A coletividade oportunizada pela convivência em grupo de terceira idade contribui para o fortalecimento das relações e oportunidades, principalmente daqueles que vivenciavam uma socialização restrita anteriormente à participação no grupo. Os discursos dos participantes refletem sobre atividades lúdicas e de lazer as quais favorecem a aproximação, o prazer, a melhora da condição física e os deixam mais desinibidos. O contato direto com outros sujeitos nestas modalidades de atividades vislumbra maior facilidade de entrosamento.

A participação de idosos em atividades lúdicas e de lazer, em grupo, representa um aspecto diferencial no rumo de suas histórias de vida, pois favorece a vivência de um estado de plenitude, bem-estar, equilíbrio biopsicossocial, facilita a socialização e oferece suporte social. Frequentar um grupo significa encontrar um espaço em que se pode partilhar afetos, o que reflete nos relacionamentos interpessoais, na disposição física e consequentemente em uma senescência ativa. Grupos dessa modalidade são vislumbrados como espaços quase exclusivos à socialização de idosos (Previato et al, 2019).

Os benefícios advindos da aproximação e entrosamento entre os participantes, não influenciam somente a formação de novos laços de amor, também fortalece as relações já existentes. Deste modo, a interação e a modalidade de atividades ofertadas é o que consolida o grupo e de forma positiva influencia a sexualidade.

A gente se sente mais vivo, aumenta a nossa disposição. As atividades que a gente faz no grupo interfere na minha relação, porque, faz eu me sentir mais viva, com mais capacidade para viver essa relação. Quase nem discutimos porque temos outras coisas para falar e se organizar para participar (P5).

É como coloquei nessa foto aqui (se referindo a uma das imagens escolhidas para compor seu almanaque) antes era um olhando para o outro, só nós dois velhos, aí viemos para cá e temos mais coisa para falar em casa, aumentou nosso companheirismo, a gente, como os meus netos falam, se "curte" mais (P11).

$\mathrm{O}$ conjunto dos discursos traz à tona o destaque que a participação no grupo de terceira idade assume frente à sexualidade de casais idosos, e revela que as atividades desenvolvidas no interior dos grupos possibilitam maior aproximação e vontade para vivenciar essas relações. Noções de interdiscurso permitem compreender que essas atividades possibilitam que esses idosos se sintam mais ativos e com maior disposição, fazendo com que estes atributos gerados por meio da interação com o grupo sejam transferidos para suas relações conjugais.

As diversas atividades propostas permitem que a rotina diária dos idosos seja preenchida e compartilhada junto a um grupo de pessoas, o que possibilita que os momentos que estão a sós possam ser vivenciados de forma mais prazerosa. Nesse 
sentido, pode-se considerar que as atividades de lazer e a convivência nesse espaço de sociabilidade favorecem o equilíbrio emocional do idoso, ampliam as oportunidades para os desafios de vivenciar a longevidade e promovem maior inclusão em diferentes contextos e situações da vida (Scortegagna, Pichler, Dametto, Gazzana \& Colussi, 2019).

O movimento de participação nos grupos de terceira idade tem desencadeado, tanto na pessoa idosa quanto na sociedade, mudanças comportamentais que fortalecem o papel social do idoso. Quanto a sexualidade, percebe-se que o grupo contribui de diferentes modos aos sujeitos participantes. O envolvimento grupal mostra-se como fator significativo para a capacidade de ultrapassar e ressignificar aspectos que compõem a formação do sujeito (Previato et al., 2019).

Eu até brinco com o (...) (se referindo ao nome do companheiro) que agora ele me beija mais. Até pedi para ele se é porque aqui no grupo a gente se diverte bastante, brincamos juntos, nos abraçamos e beijamos muito entre todos nós. Se ele estava copiando o que o pessoal do grupo fazia (risos) (P11).

Ah, sabe que me esqueci de te contar, minha relação até deu uma apimentada, meu marido voltou a sentir ciúmes, porque como tenho vontade de me arrumar para vir, venho sempre cheirosa, ele fica "cheio de dedos", digo até que ele voltou a me valorizar mais (P13).

Quando vamos ficando velho não é que não exista mais sexo, claro que existe, mas, a gente não quer mais ficar tanto assim sozinhos. Então, participar do grupo faz a gente preencher vários momentos, ficamos bastante tempo com outras pessoas tendo diversão que, depois, quando estamos sozinhos aproveitamos mais, temos bastante assunto e até temos mais disposição para a "coisa" (se referindo a relação sexual). Melhora a relação sim! (P15).

A participação no grupo de terceira idade movimenta diversas esferas da vida dos integrantes. A realização de atividades compartilhadas possibilita aos participantes sentimentos de autovalorização, de entrosamento, de ludicidade e de preenchimento do tempo ocioso. A gama de influências positivas advindas da participação em grupos de terceira idade reflete também no relacionamento conjugal. Relacionamentos em que um ou ambos parceiros participam das atividades do grupo identificam a participação como "algo a mais" em sua relação.

O sucesso conjugal na velhice está ligado à intimidade, à companhia e à capacidade de expressar sentimentos verdadeiros um para o outro, numa atmosfera de segurança, carinho e reciprocidade. Entre sentimentos subjetivos, anos transcorridos e transformações físicas, a continuidade da atividade sexual na terceira idade está ligada à intimidade e ao quanto dispostos e ativos encontram-se, suscitando, deste modo, mecanismos que influenciam tais fatores, sendo o grupo de terceira idade um deles (Pinto, Reis, Santana \& Reis, 2019; Vieira; Coutinho \& Saraiva, 2016).

\subsection{Superando preconceitos e tabus no grupo de terceira idade}

A sexualidade do idoso pode estar relacionada a vários sentimentos: são as alegrias, as culpas, as vergonhas, os preconceitos e as repressões de cada um. Culturalmente tabus e preconceitos são construídos e influenciam de modo direto esse aspecto de suas vidas. A enunciação do discurso confere importância a esta circunstância quando diz:

Minha família demorou para aceitar que eu pudesse ter um "namoradinho". Um dia meu neto falou: "vó, a senhora não pode namorar, não tem idade pra isso!". Fiquei bem triste, não tive vontade de continuar, queria acabar e aceitar que eu não podia (P12).

O discurso reitera discussões já pleiteadas e conformadas na sociedade atual. Os termos "não tem idade para isso" corroboram e sinalizam a existência de formações imaginárias associadas aos sujeitos idosos, as quais perpassam culturalmente e intergerações, carreando preconceitos e tabus referentes a esta temática. O neto manifesta uma atitude que reprime a vontade de manifestar e vivenciar este aspecto da dimensão humana, desvelando, assim, a importância do apoio social recebido.

Ao longo do desenvolvimento da sociedade foram criados estereótipos que denigrem a imagem do idoso que manifesta desejos sexuais e que atrapalham a adequada compreensão dos sentimentos das pessoas com idade mais avançada. 
Submetidos a essa recriminação social começam a aceitar essa negação como um processo normal da idade. Assim, muitos idosos permanecem vítimas da repreensão e dos obstáculos que seus familiares e a sociedade aplicam sob seus desejos e vontades (Vieira; Coutinho \& Saraiva, 2016).

Aliado ao preconceito arraigado a esta temática encontra-se a sexualidade expressa como tabu, proporcionando aos idosos espaços restritos para refletirem, conversarem ou até mesmo sanarem dúvidas. A sexualidade na terceira idade é um tema negligenciado e, por vezes, pouco entendido pela sociedade, idosos e até profissionais de saúde (Carrasco, Ballesteros, Granja \& Pazos, 2019).

Estava aqui pensando sobre o que estávamos falando, de como a gente não tem espaço para falar isso. Sabe que aqui no grupo é que a gente fala sobre isso, assim entre nós, às vezes (P3).

Lá em casa acho que pensam que eu não faço mais nada, devem pensar que só saio de mãos dadas (risos), porque ninguém nunca falou nada para mim sobre isso. E é bem isso! Não temos muito lugar para falar disso não, aqui no grupo, às vezes, entre nós, a gente fala, acho que até nisso o grupo é bom (P12).

Sob esta perspectiva o grupo de terceira idade mostra-se como um espaço exclusivo, de apoio, de compreensão, onde os idosos trocam informações e experiências entre os pares sobre diversas temáticas, incluindo as repletas de estigmas e que não se sentem à vontade para conversar com familiares. A sexualidade é vista pela sociedade de maneira estigmatizada, proporcionando aos idosos poucos espaços para discutirem esse tema. Assim, os grupos de terceira idade vislumbram-se como um lócus que permite a tomada de posição sujeito, e proporciona suporte, amparo, momentos de reflexão e discussão.

As contribuições advindas do grupo, nesta esfera, fundamentam-se nas relações de proximidade, de amizade e companheirismo. Nesse sentido, mostra-se como espaço de socialização e local de escuta, contribuindo na interação, na consciência crítica e no resgate da autonomia dos idosos (Previato et al., 2019).

As falas dos participantes evidenciam, ainda, possível impacto de suas participações na autoconfiança e na superação de tabus e preconceitos relacionados ao despertar da sexualidade na terceira idade. Assim, esses espaços podem influenciar no desenvolvimento e empoderamento individual.

Quando meu neto falou que eu não podia namorar, fiquei bem triste, e acho que o grupo me ajudou nisso, porque aqui eu encontrava alegria, conversava sobre esse assunto, me davam apoio e me ajudaram a superar (P12).

O negócio é se achar a pessoa interessante, tem que namorar, tem que viver! Já passou o tempo que na nossa idade não podia mais. E aqui no grupo, com a convivência, a gente vai desenvolvendo esse pensamento (P4).

O convívio social oportunizado pela participação nas atividades grupais pode fornecer suporte, companheirismo e respeito, talvez, em virtude de os indivíduos idosos vivenciarem situações semelhantes. Reconhece-se como benefícios dos grupos de terceira idade o estabelecimento de relações, união, expressão de sentimentos, criação de vínculos e melhoria do bem-estar (Araújo, Moreira, Freitas, Silva \& Val, 2017).

Os grupos de terceira idade demonstram ser espaços que transformam esses indivíduos idosos em "maus sujeitos", ao possibilitar-lhes ferramentas interessantes para distanciar-se das formações discursivas e imaginárias construídas social e historicamente. Os segmentos "me davam apoio e me ajudaram a superar" e "e aqui no grupo, com a convivência, a gente vai desenvolvendo esse pensamento" destacam essa tomada de posição possibilitada no espaço do grupo e assumida pelos idosos participantes.

As enunciações dialógicas dos idosos participantes, durante a discussão coletiva nas dinâmicas, demonstram que o apoio gerado dentro do grupo integra também aspectos referentes à aceitação e compreensão das mudanças físicas que ocorrem no contexto do envelhecimento, culminando aos idosos uma melhor vivência da sexualidade e desta fase em suas vidas. 
A gente vai aprendendo a ficar velho com o grupo, vai envelhecendo aqui e vê que todo mundo passa pela mesma coisa. Tu escutas que contam que já não tem mais a mesma vontade de "fazer aquilo" (se referindo ao ato sexual), $e$ aí o grupo ajuda entender. E digo mais, aceitar o que vai acontecendo de mudança com a gente (P9).

O grupo ajuda a gente a entender melhor essa fase, sabe?! É porque quando a gente fica velho as coisas não funcionam mais tanto assim, já não é a maior fonte de felicidade, e aí, isso é uma tristeza. O grupo também ajuda a gente a entender melhor a velhice, a entender essas coisas que mudam (P14).

Os discursos denotam que o envelhecimento é permeado por diversas mudanças físicas e psicológicas. O grupo de terceira idade insere-se nesta instância possibilitando aos integrantes apoio para o enfrentamento da velhice, por meio do compartilhamento de experiências, vivências, da compreensão e do suporte fornecido entre os participantes, possibilitando deste modo, o (re)significar das modificações e das perdas que tangenciam a sexualidade.

Desenvolver recursos pessoais e sociais que promovam o envelhecimento como uma experiência positiva e heterogênea consequentemente repercutem na sexualidade e mostra-se como uma possível estratégia para ser explorada nas atividades promovidas pelos grupos de terceira idade (Carrasco et al, 2019; Vieira; Coutinho \& Saraiva, 2016). Assim, os grupos podem ser reconhecidos como benéficos para a proteção do idoso, distanciando-os de atitudes negativas e favorecendo a motivação e o apoio emocional (Oliveira et al., 2019).

\subsection{A sexualidade compreendida de forma multidimensional no contexto de participação em grupos de terceira idade}

A sexualidade pode ser compreendida como uma resposta à capacidade física e emocional dos estímulos, indo além do impulso e do ato sexual (Bazza \& Navarro, 2019). Frente a esse contexto, vislumbra-se a sexualidade como uma dimensão humana presente em toda a trajetória existencial, podendo ser vivenciada de diferentes maneiras em cada momento, manifestando-se de acordo com especificidades físicas, psíquicas, biológicas, culturais e sociais.

Os discursos no âmbito das dinâmicas retratam que a sexualidade não é um processo simples, objetivo e estático, é amplo e multidimensional, sendo o grupo de terceira idade compreendido pelos idosos como um lócus que apresenta influência para o despertar da sexualidade e desta perspectiva.

Sexualidade eu entendo como os beijos, abraços, carinho, preocupação, se sentir valorizada. E te digo que isso eu acho no grupo, não é só com homem não! Um dia já até achei que era só sexo, mas não é (P14).

Eu entendo a sexualidade como qualquer tipo de prazer, porque prazer é uma coisa normal, tem muita gente que na terceira idade ainda tem prazer fazendo sexo, eu, por exemplo, dar risada é um prazer para mim. Só o carinho e o afeto para mim nesta fase já são suficientes (P6).

Na terceira idade temos outras formas de ter prazer, mesmo que a prática do sexo não esteja mais presente, tem outras formas de se alegrar, não é só aquilo não! A gente se sente bem e o grupo traz vários outros prazeres e mostra que a vida é bela (P1).

Esse casal aqui (se referindo a imagem selecionada para compor seu almanaque) representa o carinho, o amor e a amizade, então não é necessário o sexo e isso o grupo traz (P8).

Observa-se nas enunciações dialógicas que a compreensão do termo sexualidade assume, para os idosos participantes significado multidimensional tornando, assim, o ato sexual como um atributo que compõem, juntamente com o carinho, o lazer, a diversão, a amizade, e os sentimentos de autovalorização, e em igual relevância, este aspecto da vida humana.

A compreensão de que a sexualidade pode manifestar-se sem a expressão do ato sexual permite aos idosos uma melhor vivência deste aspecto de suas vidas e demonstra a relação desta com sentimentos de prazer em busca da satisfação pessoal (Soares \& Meneghel, 2021). Sob esta perspectiva o grupo de terceira idade, por meio de suas atividades e participantes, possibilita esses fatores que também tangenciam a sexualidade, tendo em vista que na perspectiva dos idosos a sexualidade pode ser alcançada independentemente da presença de um companheiro (a). 
Ao vislumbrar a transversalidade da sexualidade, compreende-se que mesmo que os idosos não estejam ativamente engajados em relações sexuais ou sequer pensem no assunto por um longo tempo, eles ainda devem ser reconhecidos como seres humanos sexuais. Os idosos, geralmente, percebem a sexualidade como uma expressão de paixão, afeto, admiração e lealdade; uma renovação do romance; uma afirmação geral da vida, especialmente a expressão da alegria; e uma oportunidade contínua de crescimento e experiência (Messelis, Kazer \& Gelmetti, 2019; Vieira, Coutinho \& Saraiva, 2016).

A compreensão da sexualidade é subjetiva e sofre influência de diversos fatores históricos, culturais, sociais e de gênero que permeiam a vida dos indivíduos. A compreensão multidimensional observada no discurso dos idosos inclui também a dimensão da sexualidade enquanto sexo.

Sexo é muito subjetivo. Na nossa idade para quem ainda tem desejos é bom, mas se não, pode ser substituído por outros prazeres (P9).

Não existe um padrão claro para a sexualidade em pessoas idosas. Existem, no entanto, diferentes fatores biopsicológicos que afetam a sexualidade à medida que envelhecemos. Os idosos são as mesmas pessoas que já foram jovens e, portanto, é improvável que seus pensamentos, fantasias, desejos, habilidades e expressões sexuais passem por uma mudança drástica. No entanto, existem mudanças nos hormônios, na saúde e na disponibilidade e qualidade do companheirismo, o que pode ter um impacto na saúde sexual (Messelis, Kazer \& Gelmetti, 2019).

A compreensão da sexualidade enquanto estrutura complexa, subjetiva e ampla permite um novo olhar perante o vivenciar da sexualidade, reconhecendo a corporeidade, a intimidade, a estima e a afeição como fatores determinantes a esse processo (Messelis, Kazer, \& Gelmetti, 2019). O grupo de terceira idade permite a continuidade de ampliação e compreensão desta perspectiva, além da concepção biológica, envolvendo todos os sentidos e abrangendo um conjunto de experiências e emoções que se exprimem na continuidade do prazer que acompanha a trajetória existencial.

Acho que posso até te dizer que o grupo faz parte da sexualidade do meu casamento, tu podes até achar estranho isso, mas até eu estou! Nunca tinha parado para pensar nisso. Mas, é isso! O grupo entra nas partes que meu casamento já não consegue preencher, como por exemplo, sabe que ganho mais carinho aqui do que no meu casamento (P13).

E aqui (se referindo a uma das imagens escolhida para compor seu almanaque), esse carro, é como se nós tivéssemos ido fazer uma viagem, mas pifou, e virou divertimento. E é mais ou menos assim com o sexo, muita coisa muda, nosso corpo muda, nossos desejos mudam, e aí vêm os participantes do grupo, os bailes, as atividades de canastra e de câmbio e traz a diversão que é a melhor forma de prazer para mim (P7).

Os discursos recodificam a influência que o grupo de terceira idade assume frente à sexualidade de idosos, demonstrando-a como uma realidade humana complexa e multifatorial que não pode ser reduzida a um único foco, pois tem diversas repercussões sociais. A sexualidade apresenta-se como pertencente à existência humana e constitui-se com uma atividade de exploração, podendo receber influência de diversas atividades que ocorrem no espaço dos grupos de terceira idade.

A realização das atividades cria possibilidades para que o idoso faça escolhas prazerosas que propiciem a manifestação da sexualidade, e ocupe seu tempo de maneira criativa, de forma a mantê-lo ativo. Em vista disso, pode-se reconhecer a sexualidade enquanto aspecto multidimensional, compreensão que assume relevância para a faixa etária em questão, e mostra novas perspectivas e influências para o despertar da sexualidade neste âmbito. Portanto, reconhece-se que os sentimentos, afetos, carinho e diversão podem ser encontrados no grupo, por meio das atividades, relações, vínculos estabelecidos, e que para os idosos participantes, são manifestações da sexualidade.

A sexualidade é um componente fundamental da qualidade de vida, essencial para manter as relações interpessoais saudáveis, o autoconceito e um senso de integridade. É natural que os idosos procurem espaços favoráveis à sua satisfação, 
podendo encontrar em grupos sociais com os quais se identificam o local para estabelecer suas relações e criar novas experiências e vínculos com a sociedade (Vieira, Coutinho \& Saraiva, 2016; Pinto et al., 2019).

A compreensão multidimensional, associada neste estudo, à sexualidade abarca também a necessidade da autovalorização, da autoestima, e do bem-estar. Observa-se no discurso dos participantes que o grupo se apresenta como espaço que propicia sentimentos de valorização aos participantes, o que reflete na sexualidade deles.

Eu tenho vontade de me arrumar para vir para o grupo, de ficar cheirosa, porque, sei que aqui vou abraçar todos quando chegar. É aquela coisa de se sentir mais valorizada, de não se sentir acabada (P13).

Antes do grupo me sentia sozinha, só olhando para o espelho, me sentindo perdida, sem valorização. Entrei no grupo e comecei a receber carinho, um aperto de mão, um abraço apertado, o sorriso, as palavras (P7).

Aqui eu me sinto valorizada e isso é uma manifestação da sexualidade (P9).

O convívio social oportunizado pela participação no grupo desperta o cuidar da aparência e implica em sentimentos de estima e autoestima, vinculados pelos participantes como uma das dimensões da sexualidade. As vivências e trocas de experiências positivas, mostram-se repletas de emoções, movimentam suas vidas e geram uma sensação de bem-estar.

Sob esta perspectiva, observa-se que apesar de algumas dificuldades, que são inerentes aos seres humanos, os sentimentos de valorização dos referidos idosos são um dos fatores que estimulam o desvelar da sexualidade. Destaca-se que sexualidade está presente em todos os atos da vida e é determinante de um modo particular e individual de ser, de manifestarse, comunicar-se, sentir e expressar. Desse modo, é necessária uma visão ampla e dinâmica, compreendendo-a como experiência, resultante da subjetividade, e que desvela incontáveis maneiras de expressar e vivenciar o prazer (Uchôa et al, 2016; Vieira, Coutinho \& Saraiva, 2016).

\section{Considerações Finais}

Os dados construídos coletivamente evidenciaram que o grupo de terceira idade possibilita um espaço de expressão da sexualidade dos participantes. O grupo apresenta-se como espaço que permite expressão da sexualidade e de troca de experiências. A sexualidade, em seu conceito multidimensional, apresenta-se como elemento fundamental para o bem-estar e qualidade de vida na terceira idade.

Perfilhar a sexualidade como parte integrante da personalidade do ser humano e como uma necessidade humana básica contribui para a qualidade de vida dos idosos e para a qualificação do atendimento oportunizado pelos profissionais. Além disso, ao reconhecer os grupos de terceira idade como espaços de vivência de idosos em que se criam valores, maneiras de pensar, de sentir e de agir facilitando a transformação das relações sociais e a preservação da autonomia do idoso e consequentemente contribui-se para a integralidade na saúde.

Assim, espera-se que o presente estudo possa suscitar reflexões que culminem em novas ações de profissionais da saúde, frente a esse movimento já estruturado. Bem como, para a ampliação do olhar frente ao sujeito idoso, conhecendo os aparatos construídos socialmente à essa faixa etária e que interferem na condução dos processos de promoção e prevenção da saúde.

\section{Referências}

Andrade, N. A., Nascimento, M. M. P., Oliveira, M. M. D., Queiroga, R. M., Fonseca, F. L. A., Lacerda, S. N. B., \& Adami, F. (2014). Percepção de idosos sobre grupo de convivência: estudo na cidade de Cajazeiras -PB. Rev. Bras. Geriatr. Gerontol., 17(1): 39-48.

Araújo, L. S. A., Moreira, A. C. A., Freitas, C. A. S. L., Silva, M. A. M., \& Val, D. R. (2017). Idosos e grupos de convivência: motivos para a não adesão. SANARE, Sobral, 16(1): 58-67. 
Bazza, A. B., \& Navarro, P. (2019). Discursos sobre o idoso: sexualidade e subjetividade. Linguagem em (Dis)curso, 19(2), 293-309. 10.1590/1982-4017190204-5618.

Cabral, I. E., \& Moraes, J. R. M. M. de. (2015). Familiares cuidadores articulando rede social de criança com necessidades especiais de saúde. Rev. Bras. Enferm., 68(6):1078-85. 10.1590/0034-7167.2015680612i..

Carrasco, M. H., Ballesteros, S. L. F., Granja, N. J., \& Pazos, M. C. (2019). Características de la esfera sexual en pacientes adultos mayores. Medicina de Familia, 45(1):37-43. 10.1016/j.semerg.2018.09.007.

Carvalho, C. F., Bezerra, A., Castro, J. R., Nascimento, A. C., Pereira, B. M. M., Silva, C. C., Gomes, S., Costa, S. M., \& Gonçalves, C. A. (2016). Sexualidade e qualidade de vida dos idosos da rede crescer - conviver de Uberlândia - MG. Revista Eletrônica da Reunião Anual de Ciência, 6(1).

Instituto Brasileiro de Geografia e Estatística. (2018). Projeção da População 2018: número de habitantes do país deve parar de crescer em 2047. https://agenciadenoticias.ibge.gov.br/agencia-sala-de-imprensa/2013-agencia-de-noticias/releases/21837-projecao-da-populacao-2018-numero-de-habitantesdo-pais-deve-parar-de-crescer-em-2047.

Marques, A. D. B., Silva, R. R. da., Sousa, S. dos S., Santana, R. da S., Deus, S. R. M. de., \& Amorim, R. F. de. (2015). A vivência da sexualidade de idosos em um centro de convivência. R. Enferm. Cent. O. Min., 5(3): 1768-1783. 10.19175/recom.v5i3.913.

Messelis, E., Kazer, M. W., \& Gelmetti J. A. (2019). Sexuality, Intimacy, and Healthy Aging. In: COLL, P. (eds) Healthy Aging. Springer, Cham.

Miranda, G. M. D., Mendes, A. da C. G., \& Silva, A. L. A. da. (2016). O envelhecimento populacional brasileiro: desafios e consequências sociais atuais e futuras. Rev. Bras. Geriat. e Gerontol., 19(3): 507-519.

Oliveira, A. G. de., Abreu, S. S. S. de., Macedo, M. A. S. S., Duarte, S. F. P., Reis, L. A. dos., \& Lima, P. V. (2019). Grupos de convivência como suporte na prevenção da depressão em idosos. Rev Enferm Contemp., 8(1):17-24.

Oliveira; E. L., Neves, A. L. M. das., \& Silva, I. R. da. (2018). Sentidos de sexualidade entre mulheres idosas: relações de gênero, ideologias mecanicistas e subversão. Psicol. Soc, 30:e166019.

Pêcheux, M. (2009). Semântica e Discurso: uma crítica à afirmação do óbvio. (4ª ed.): Ed. da UNICAMP. Trad. Brasil. ORLANDI, E. P. et al.

Pinto, M. X. R., Reis, L. A. dos., Santana, E. dos S., \& Reis, L. A. dos. (2019). Sexualidade e envelhecimento: a percepção de idosos participantes de grupo de convivência. Fisioterapia Brasil, 20(1):43-49.

Previato, G. F., Nogueira, I. S., Mincoff, R. C. L., Jaques, A. E., Carreira, L., \& Baldissera, V. D. A. (2019). Grupo de convivência para idosos na atenção primária à saúde: contribuições para o envelhecimento ativo. Rev. pesqui. cuid. fundam., 11(1):173-180.

Reis, J. L. dos., \& Cassino, L. (2017). A influência do grupo de convivência na redução de adoecimentos psíquicos na terceira idade. Revista Brasileira de Ciências da Vida, 5(3).

Soares, K. G., \& Meneghel, S. N. O silêncio da sexualidade em idosos dependentes. Ciência \& Saúde Coletiva, 26(1), 129-136. 10.1590/141381232020261.30772020 .

Saraiva, R., Rosas, A., Marques, E., \& Valente, G. (2018). A sexualidade do idoso no contexto da consulta de enfermagem: uma análise fenomenológica de luso-brasileiros. Millenium, 2(5):63-71.

Scortegagna, H. M., Pichler, N. A., Dametto, J., Gazzana, S., \& Colussi, E. L. (2019). Cuidado de si em um grupo de convivência de idosas. Rev. bras. geriatr. Gerontol. 22(1):e180164.

Schoffen, L. L., \& Santos, W. L. dos. (2018). A importância dos grupos de convivência para os idosos como instrumento para manutenção da saúde. Rev. Cient. Sena Aires, 7(3):160-70.

Uchôa, Y. da S., Costa, D. C. A. da., Junior, I. A. P. da S., Silva, S. de T. S. E. de., Freitas, W. M. T. de M., \& Soares, S. C. da S. (2016). A sexualidade sob o olhar da pessoa idosa. Rev. Bras. Geriatr. Gerontol., 19(6):939-949.

Valer, D. B., Bierhals, C. C. B. K., Aires, M., \& Paskulin, L. M. G. (2015). O significado de envelhecimento saudável para pessoas idosas vinculadas a grupos educativos. Rev. Bras. Geriatr. Gerontol., 18(4):809-819.

Vieira, K. F. L., Coutinho, M. da P. de L., \& Saraiva, E. R. de A. (2016). A sexualidade na velhice: representações sociais de idosos frequentadores de um grupo de convivência. Psicologia: Ciência e Profissão, 36(1):196-209. 